\title{
Influencing Factors Analysis and Simulation Calibration of Restitution Coefficient of Rice Grain
}

\author{
Jinwu Wang ${ }^{1}{ }^{\mathbb{D}}$, Changsu Xu ${ }^{1}$, Yanan Xu ${ }^{1}$, Ziming Wang ${ }^{1}$, Xin Qi ${ }^{1}$, Jinfeng Wang ${ }^{1}$, Wenqi Zhou ${ }^{1}$, \\ Han Tang 1,2,*(D) and Qi Wang ${ }^{1, *}$
}

1 College of Engineering, Northeast Agricultural University, Harbin 150030, China; jinwuw@neau.edu.cn (J.W.); ChangsuXu@neau.edu.cn (C.X.); YananXu@neau.edu.cn (Y.X.); wangziming970115@163.com (Z.W.); XinQi@neau.edu.cn (X.Q.); jinfeng_w@126.com (J.W.); zwq@neau.edu.cn (W.Z.)

2 Key Laboratory of Crop Harvesting Equipment Technology of Zhejiang Province, Jinhua 321007, China

* Correspondence: tanghan@neau.edu.cn (H.T.); wangqi@neau.edu.cn (Q.W.); Tel.: +0451-5519-0950 (H.T. \& Q.W.)

Citation: Wang, J.; Xu, C.; Xu, Y.; Wang, Z.; Qi, X.; Wang, J.; Zhou, W.; Tang, H.; Wang, Q. Influencing Factors Analysis and Simulation Calibration of Restitution Coefficient of Rice Grain. Appl. Sci. 2021, 11, 5884.

https://doi.org/10.3390/app11135884

Academic Editor: Joachim Müller

Received: 29 March 2021

Accepted: 22 June 2021

Published: 24 June 2021

Publisher's Note: MDPI stays neutral with regard to jurisdictional claims in published maps and institutional affiliations.

Copyright: (c) 2021 by the authors. Licensee MDPI, Basel, Switzerland. This article is an open access article distributed under the terms and conditions of the Creative Commons Attribution (CC BY) license (https:// creativecommons.org/licenses/by/ $4.0 /)$.
Featured Application: This study provides a method for the determination of restitution coefficient of small grain, and provides a reference for the optimization design of threshing cylinder and cleaning device of combine harvester and high-speed precision seeder.

\begin{abstract}
It is difficult to determine the coefficient of restitution accurately due to the small size, light weight, and complex influencing factors of rice grain. In the study, the experimental principle of restitution coefficient was described by the impact method, and the restitution coefficients of four typical rice varieties in Northeast China were measured. According to the orthogonal experiment, the primary and secondary factors affecting the restitution coefficient of rice grain were collision material, spring compression (initial collision velocity), moisture content, and rice variety. A single factor test was carried out for the significant factors, and the results showed that: The restitution coefficient of rice grain to a Q235 steel plate, plexiglass plate, seed plate, and rubber plate decreased in turn, and the restitution coefficient gradually decreased with the increase of spring compression (initial collision velocity), and with the increase of water content. The restitution coefficient was obtained by a bench test and simulation test, and the results were 0.429 and 0.423 , respectively. The reason for the error was discussed and analyzed, which effectively verified the validity of the measurement of the restitution coefficient of small grain size. This study provides a method for the determination of the restitution coefficient of small grain, and provides a reference for the optimization design of threshing and a cleaning device of the combine harvester and high-speed precision seeder.
\end{abstract}

Keywords: rice grain; restitution coefficient; impact method; influencing factors; high-speed camera system; experiment; simulation and comparison

\section{Introduction}

Rice is one of the most important food crops in the world; the annual planting area in China is 30 million hectares. In 2020, the comprehensive mechanization level of rice cultivation and harvest exceeded 85\% [1-3]. As the representative main producing area of high-quality rice, Northeast China plays an extremely important role in ensuring food security and economic stability [4]. The characteristics of rice grain materials have a direct impact on the filling mechanism and separation characteristics of the seeding device, and it is also an important index to reveal the impact and collision mechanism of rice grain in the header and threshing drum of the combine harvester [5]. Therefore, it is of great significance to explore the material characteristics of rice grain for the development of a high-speed precision seeder, reducing the harvest loss rate and improving the comprehensive mechanization level. The material characteristics of rice grain mainly include triaxial 
size, 1000 grain weight, the natural repose angle, the restitution coefficient, and so on [6]. It is difficult to measure the restitution coefficient accurately because of the complex factors.

The determination of the restitution coefficient mainly includes the velocity definition method, impulse definition method, and energy definition method [7-9]. Among them, the velocity definition method and the impulse definition method are the ratio of the normal relative separation velocity and the normal relative approaching velocity at the contact point after the collision of two objects, which are mainly applicable to the centripetal collision problem of spherical or nearly spherical objects. The energy definition method is the arithmetic square root of the ratio of the kinetic energy change value in the deformation recovery stage of the system to the kinetic energy change value in the compression stage of the system, which is suitable for irregular objects. Many scholars calculated the restitution coefficient by the ratio of the velocity before and after the gravity of the material falls to the collision plane. Feng et al. [10] designed a test device for the restitution coefficient of the potato based on the dynamic theory of particle impact on a fixed surface, and the restitution coefficient of potato tubers at harvest was determined. Liu et al. [11] established the collision model of sunflower seeds and measured the restitution coefficient. Yang et al. [12] established the theoretical model and experimental device of the restitution coefficient of Ricinus communis based on the principle of collision dynamics and the kinematics equation. Horabik et al. [13] measured the relationship between impact force and the time of different types of peas by using a high-speed camera and piezoelectric ceramic sensor, and the restitution coefficient of seeds was calculated. The above related research focuses on the relatively heavy crops, and the restitution coefficient can be directly solved by the principle of free fall kinematics.

The accurate determination of the restitution coefficient of agricultural materials has an important guiding role in the research of related agricultural machinery and equipment [14]. With the application of computer technology, the coupling simulation of agricultural materials and mechanical components has attracted more and more attention. $\mathrm{Xu}$ et al. [15] simulated and analyzed the crushing process of cucumber straw based on the discrete element method, which provided theoretical guidance for the development of efficient cucumber straw crushing equipment. Lei et al. [16] used the DEM-CFD coupling method to simulate the movement of seeds in the pneumatic seeder, and explored the influence of the area, length, and velocity of the air flow tube on the movement of seeds. Zhan et al. [17] established a model of flexible rice straw by EDEM, and simulated the effect of different threshing gaps, and effectively improved the threshing effect by changing the diameter of the threshing drum and adjusting the threshing gap. Horabik et al. [18] simulated the stress distribution of pea seeds on the silo wall by DEM, and the different trends of stress radial distribution during seed movement were explored. To ensure the accuracy and reliability of the simulation results, it is necessary to set reasonable and effective material characteristic parameters in the above related studies.

Due to the small size and light weight of rice grain, there were some disadvantages in the traditional gravity natural falling method. When the height was too high, the rice grain was easy to be affected by the air resistance, resulting in the deviation of the falling trajectory. When the height was too low, the rice grain was not easy to spring up on the test plane and roll down. Both of them led to an inaccurate determination of the restitution coefficient. In this paper, an impact method was proposed to measure the restitution coefficient of rice grain, and a related test device was designed. By measuring the velocity changed in $x, y$, and $z$ directions before and after the impact based on the principle of mirror reflection, it can effectively avoid solving the energy changes of the whole system by the energy definition method. The simulation calibration was based on the discrete element method. The research provides an effective reference for the accurate determination of the restitution coefficient of rice grain with small size, and provides accurate data support for the simulation design of a high-speed precision seeder, a combine harvester, and other related mechanical parts. 


\section{Materials and Methods}

\subsection{Materials}

The typical rice varieties "Longjing 29", "Wuyoudao 4", "Jijing 88", and "Shennong 9903" widely planted in the main rice producing areas of Northeast China were selected as test samples, as shown in Figure 1.

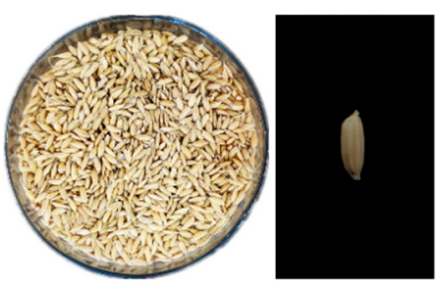

(a)

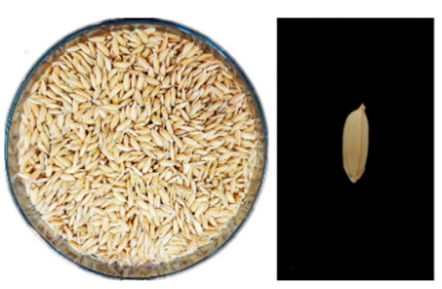

(b)

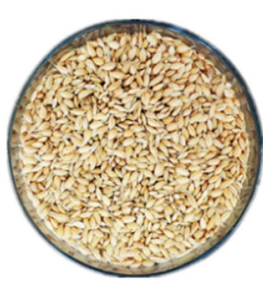

(c)

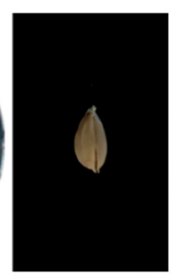

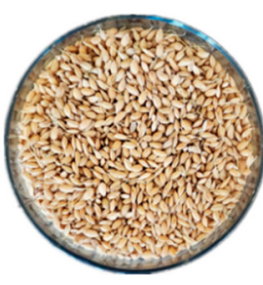

(d)

Figure 1. Typical rice varieties in main rice producing areas of Northeast China: (a) Longjing 29; (b) Wuyoudao 4; (c) Jijing 88; (d) Shennong 9903.

To provide effective data support for the establishment of the later discrete element model, the main material parameters such as the triaxial size and 1000 grain weight of 1000 full and undamaged rice grains were measured. The test was repeated for 3 times, and the average value was taken as shown in Table 1.

Table 1. The main parameters of typical rice varieties.

\begin{tabular}{ccccccccc}
\hline \multirow{2}{*}{ Varieties } & \multicolumn{2}{c}{ Length } & \multicolumn{2}{c}{ Width } & \multicolumn{2}{c}{ Thickness } & \multicolumn{2}{c}{ 1000 Grain Weight } \\
\cline { 2 - 8 } & $\begin{array}{c}\text { Mean } \\
\text { Value/mm }\end{array}$ & $\begin{array}{c}\text { Standard } \\
\text { Devia- } \\
\text { tion }\end{array}$ & $\begin{array}{c}\text { Mean } \\
\text { Value/mm }\end{array}$ & $\begin{array}{c}\text { Standard } \\
\text { Devia- } \\
\text { tion }\end{array}$ & $\begin{array}{c}\text { Mean } \\
\text { Value/mm }\end{array}$ & $\begin{array}{c}\text { Standard } \\
\text { Devia- } \\
\text { tion }\end{array}$ & $\begin{array}{c}\text { Mean } \\
\text { Value/g }\end{array}$ & $\begin{array}{c}\text { Standard } \\
\text { Devia- } \\
\text { tion }\end{array}$ \\
\hline Longjing 29 & 5.86 & 0.16 & 2.10 & 0.08 & 1.86 & 0.07 & 26.2283 & 0.89 \\
Wuyoudao 4 & 6.20 & 0.09 & 2.33 & 0.04 & 2.14 & 0.06 & 26.8745 \\
Jijing 88 & 4.37 & 0.11 & 2.51 & 0.05 & 2.07 & 0.06 & 22.5530 & 0.75 \\
Shennong 9903 & 4.75 & 0.15 & 2.79 & 0.10 & 2.31 & 0.11 & 24.8729 & 0.67 \\
\hline
\end{tabular}

Relevant instruments were needed in the test, mainly including vernier caliper, electric blast drying oven, electronic balance, high-speed CMOS camera, etc. The main parameters of the instruments are shown in Table 2.

According to the common contact materials of rice seeds in the process of sowing and harvesting, the rubber plate, Q235 steel plate, plexiglass plate, and seed plate (the rice seeds were arranged and adhered to the plastic plate with tweezers to reduce the gap between the grains as much as possible) were selected in the collision test, as shown in Figure 2.

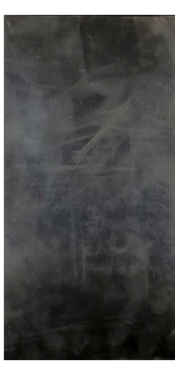

(a)

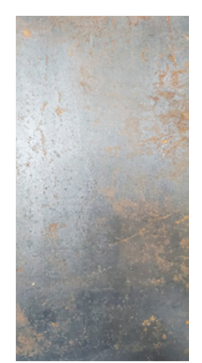

(b)

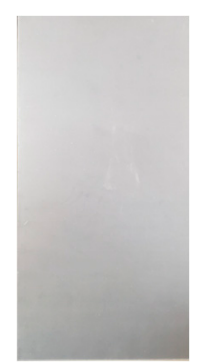

(c)

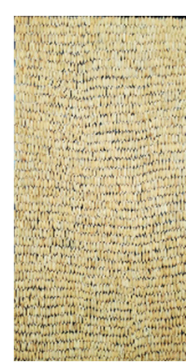

(d)

Figure 2. Contact materials: (a) rubber plate; (b) Q235 steel plate; (c) plexiglass plate; and (d) seed plate. 
Table 2. The main parameters of instruments.

\begin{tabular}{|c|c|c|c|}
\hline Equipment & Technical Parameter & Diagram & Application \\
\hline $\begin{array}{l}\text { DL91150 digital vernier } \\
\text { caliper }\end{array}$ & $\begin{array}{l}\text { Measuring range: } 0-150 \mathrm{~mm} \\
\text { Measurement accuracy: } \pm 0.03 \mathrm{~mm} \\
\text { Resolving power: } 0.01 \mathrm{~mm}\end{array}$ & $\frac{1}{1}=$ & $\begin{array}{l}\text { Measurement of rice grain } \\
\text { triaxial size }\end{array}$ \\
\hline $\begin{array}{l}\text { DZF6051 electric blast } \\
\text { drying oven }\end{array}$ & $\begin{array}{c}\text { Temp Accuracy: } \pm 1{ }^{\circ} \mathrm{C} \\
\text { Studio size: }(415 \times 370 \times 345) \mathrm{mm} \\
\text { Heating rate: } 30 \mathrm{~min}\end{array}$ & & $\begin{array}{l}\text { Controlling the moisture } \\
\text { content of rice grain after } \\
\text { harvest }\end{array}$ \\
\hline $\begin{array}{l}\text { FA1004 electronic } \\
\text { analytical balance }\end{array}$ & $\begin{array}{c}\text { Range: } 100 \mathrm{~g} \\
\text { Index value: } 0.1 \mathrm{mg} \\
\text { Outer box size: }(500 \times 310 \times 450) \mathrm{mm}\end{array}$ & & $\begin{array}{c}\text { Measurement of rice grain } \\
\text { weight before and after } \\
\text { drying }\end{array}$ \\
\hline $\begin{array}{l}\text { PCO high-speed CMOS } \\
\text { camera }\end{array}$ & $\begin{array}{l}\text { Resolving power: } 1296 \times 1024 \\
\text { Spectral range: } 290-110 \mathrm{~nm} \\
\text { ISO sensitivity: } 1250-16,000\end{array}$ & & $\begin{array}{l}\text { Dynamic photography of } \\
\text { the state of rice grain } \\
\text { collision, easy to calculate } \\
\text { the speed }\end{array}$ \\
\hline
\end{tabular}

\subsection{Methods}

To study the effect of different rice grain moisture contents on the restitution coefficient, the rice grain was treated by the water method [19]. The moisture content was determined by the $105^{\circ} \mathrm{C}$ drying method [20], and the drying instrument was the DZF6051 electric blast drying oven (Qingdao Mingbo Environmental Protection Technology Co., Ltd., Qingdao, China). During the measurement, we put the rice grain into the aluminum box, weighed the mass before drying, and put it in the drying box. Then, we kept it at $105^{\circ} \mathrm{C}$ for different times, took out the aluminum box and cooled it to room temperature, weighed the mass after drying, and calculated the moisture content of rice grain. The restitution coefficient of rice grain was calculated by the velocity ratio before and after collision based on the impact method.

The test-bed was mainly composed of mirror, coordinate paper, impact device (ring handle, spring, spring ruler, seed sticking plate, limit baffle, seed dropping opening), highspeed camera, computer, and collision platform $\left(0-75^{\circ}\right.$ adjustable), as shown in Figure 3.

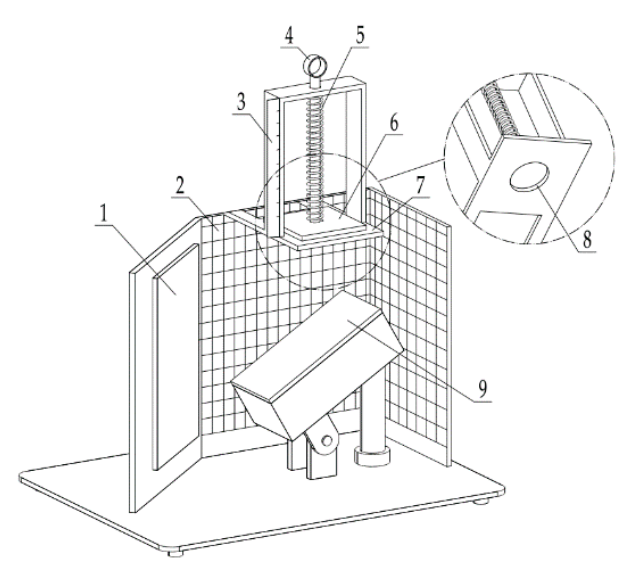

(a)

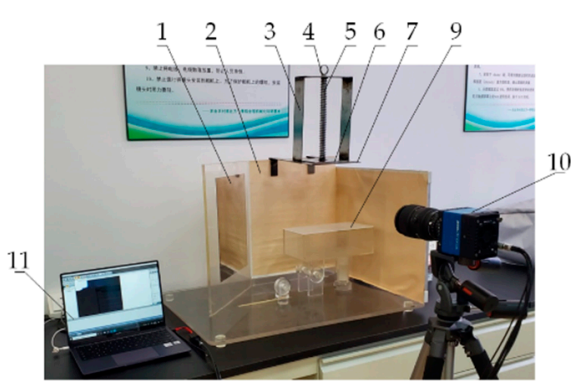

(b)

Figure 3. Test for determination of coefficient of restitution: (a) schematic diagram of impact test-bed; (b) overall structure. 1. Mirror; 2. coordinate paper; 3. spring ruler; 4. ring handle; 5 . spring; 6. seed sticking plate; 7. limit baffle; 8 . seed dropping opening; 9 . collision platform; 10. high-speed camera; and 11. computer. 
According to the principle of specular reflection imaging, a $135^{\circ}$ angle between the spatial reference wall and the reflecting mirror was designed [21]. The coordinate grid paper with a unit scale of $5 \mathrm{~mm}$ was pasted on the spatial reference wall, which was convenient for the high-speed camera to calibrate and measure the data of rice grain bouncing. The camera platform was used to fix the high-speed camera in a horizontal position and put it on the space reference wall. The plates of different materials were fixed on the collision platform to realize the collision and bounce between rice seeds and various materials.

Before the test, we adjusted the test-bed to the level, placed the contact material plate, and turned on the high-speed camera. In the test, the single rice seed was gently placed under the seed sticking plate (the adhesive force of the seed sticking plate is small and can be ignored). The ring handle was pulled vertically to compress the spring to a certain distance and release it rapidly, and the impact device dropped rapidly under the action of elastic force. When touching the limit stop, it stopped moving. Then, the rice grain broke free from the bondage of the sticky seed plate and rushed to the contact material plate on the impact platform at a certain initial speed. Using the high-speed camera to measure the spatial displacement of rice grain in the spatial reference wall and mirror, the restitution coefficient between rice grain and various materials can be analyzed and calculated.

\subsection{Test Principle}

The restitution coefficient is an index to measure the rebound ability of granular materials. Based on the principle of kinematics, the composite value of the velocity components of rice grain before and after collision along three coordinate axes is measured, and the coefficient of restitution is calculated [22].

$$
e=\frac{v_{t}}{v_{0}}
$$

where $e$ is the restitution coefficient between rice grain and tested materials; $v_{t}$ is the instantaneous rebound velocity of rice grain after collision, $\mathrm{m} / \mathrm{s}$; and $v_{0}$ is the instantaneous falling velocity of rice grain before collision, $\mathrm{m} / \mathrm{s}$.

According to the collision state between rice grain and contact materials, the falling collision process of rice grain is analyzed. It is assumed that the rice grain fall from the seed sticking plate under impact at a certain initial velocity and collide with the horizontal material plane (the collision platform is horizontal, i.e., the collision angle is $0^{\circ}$ ). The horizontal space rectangular coordinate system $x y z$ was established, as shown in Figure 4a. Before the collision, the rice grain accelerates uniformly in the vertical direction, and the coordinate value of the spatial reference wall before the $m$ frame is $\left(y_{m}, z_{m}\right)$; the coordinate value in the mirror is $\left(x_{m}, z_{m}\right)$. The coordinate values of the space reference wall at the moment of collision are $\left(y_{0}, z_{0}\right)$. In the mirror, the coordinates are $\left(x_{0}, z_{0}\right)$. In this case, the values of $x_{0}$ and $x_{m}, y_{0}$, and $y_{m}$ are equal.

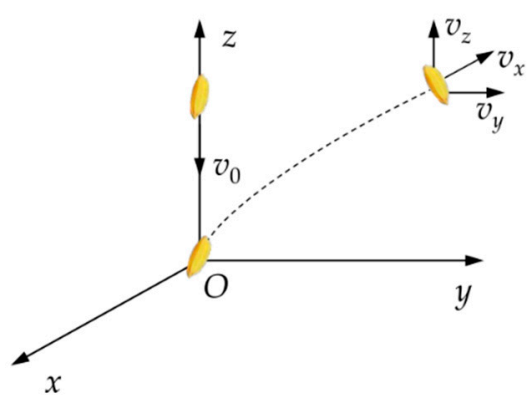

(a)

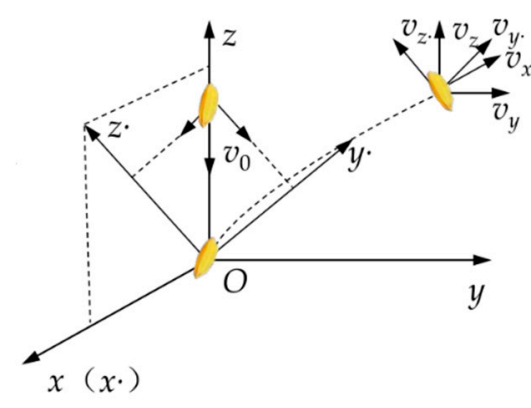

(b)

Figure 4. Kinematics analysis of rice grain in collision process: (a) simplified model of collision with horizontal collision platform; (b) simplified model of collision with inclined collision platform. 
In the vertical direction, the rice grain is uniformly accelerated, and the instantaneous velocity in the middle is equal to the average velocity in this period.

$$
\bar{v}_{m}=\frac{z_{m}-z_{0}}{t_{m}}
$$

The instantaneous velocity before the collision between the rice grain and the collision platform is as follows:

$$
v_{0}=\bar{v}_{m}+\frac{1}{2} g t_{m}
$$

The combined Formulas (2) and (3) are as follows:

$$
v_{0}=\frac{z_{m}-z_{0}}{t_{m}}+\frac{1}{2} g t_{m}
$$

By decomposing the separation velocity of rice grains after collision, the separation velocity along the triaxial direction in the three-dimensional space is obtained as follows:

$$
v_{t}=\sqrt{v_{x}^{2}+v_{y}^{2}+v_{z}^{2}}
$$

where $v_{x}$ is the partial velocity of rice grain in $x$ direction after collision, $\mathrm{m} / \mathrm{s} ; v_{y}$ is the partial velocity of rice grain in $y$ direction after collision, $\mathrm{m} / \mathrm{s}$; and $v_{z}$ is the partial velocity of rice grain in $z$ direction after collision, $\mathrm{m} / \mathrm{s}$.

Equations (4) and (5) are substituted into Equation (1), and the restitution coefficient between rice grain and horizontal test material is obtained.

$$
e=\frac{v_{t}}{v_{0}}=\frac{2 \mathrm{t}_{m} \sqrt{v_{x}^{2}+v_{y}^{2}+v_{z}^{2}}}{2\left(z_{m}-z_{0}\right)+g t_{m}^{2}}
$$

On this basis, the bouncing motion of rice grains in the process of collision with the inclined collision platform was analyzed, as shown in Figure $4 \mathrm{~b}$. The horizontal space coordinate system $x y z$ is transformed into the inclined space coordinate system $x^{\prime} y^{\prime} z^{\prime}$ (the collision platform was inclined at a certain angle; the collision angle is $\alpha_{i}$ ). The displacement relation between the coordinate systems is obtained.

$$
\left\{\begin{array}{l}
x^{\prime}=x \\
y^{\prime}=z \cos \alpha_{i}+y \sin \alpha_{i} \\
z^{\prime}=z \sin \alpha_{i}-y \cos \alpha_{i}
\end{array}\right.
$$

where $v_{x^{\prime}}$ is the partial velocity of rice grain in $x^{\prime}$ direction after collision, $\mathrm{m} / \mathrm{s} ; v_{y^{\prime}}$ is the partial velocity of rice grain in $y^{\prime}$ direction after collision, $\mathrm{m} / \mathrm{s}$; and $v_{z^{\prime}}$ is the partial velocity along $z^{\prime}$ direction after the collision of rice grains, $\mathrm{m} / \mathrm{s}$.

The restitution coefficient $e$ of rice grain with the inclined collision platform is decomposed into the normal restitution coefficient $e_{n}$ and the tangential restitution coefficient $e_{t}$. Then:

$$
\left\{\begin{array}{l}
e_{n}=\frac{\left|v_{z^{\prime}}\right|}{v_{0 z^{\prime}}}=\frac{2 t_{m}\left|v_{z} \sin \alpha_{i}-v_{y} \cos \alpha_{i}\right|}{\left[2\left(z_{m}-z_{0}\right)+g t_{m}^{2}\right] \sin \alpha_{i}} \\
e_{t}=\frac{\sqrt{v_{x^{\prime}}{ }^{2}+v_{y^{\prime}}{ }^{2}}}{\left|v_{0 y^{\prime}}\right|}=\frac{2 t_{m} \sqrt{v_{x}^{2}+\left(v_{z} \cos \alpha_{i}+v_{y} \sin \alpha_{i}\right)^{2}}}{\left[2\left(z_{m}-z_{0}\right)+g t_{m}^{2}\right] \cos \alpha_{i}}
\end{array}\right.
$$

Equation (8) is simplified to obtain the restitution coefficient between rice grain and the inclined collision platform after the coordinate transformation.

$$
e=\sqrt{e_{n}^{2}+e_{t}^{2}}=\frac{2 t_{m} \sqrt{v_{z}^{2}+\left[v_{z}+v_{y}\left(\tan \alpha_{i}-\frac{1}{\tan \alpha_{i}}\right)\right]^{2}+2 v_{y}^{2}+\frac{v_{x}^{2}}{\cos ^{2} \alpha_{i}}}}{2\left(z_{m}-z_{0}\right)+g t_{m}^{2}}
$$


It can be seen from Equations (6) and (9) that when the initial falling velocity of rice grain and the collision angle $\alpha_{i}$ are fixed, the restitution coefficient between rice grain and various contact materials can be obtained by measuring the displacement change of rice grain before and after collision with the high-speed camera.

The motion of rice grains after collision is decomposed into horizontal uniform motion and vertical uniform deceleration motion. The instant of rice grain bounce-off from the collision interface is sampled and recorded as the initial point. The coordinates of this point in the spatial reference wall are $\left(y_{0}, z_{0}\right)$, and in the mirror are $\left(x_{0}, z_{0}\right)$. When the rice grain bounced a certain height and moved $n$ frames, the movement time is $t_{n}$. The coordinate value in the spatial reference wall is $\left(y_{n}, z_{n}\right)$, and in the reflecting mirror is $\left(x_{n}, z_{n}\right)$. Then, the instantaneous moving speed in the horizontal direction is obtained.

$$
\begin{aligned}
& v_{x}=\frac{x_{n}-x_{0}}{t_{n}} \\
& v_{y}=\frac{y_{n}-y_{0}}{t_{n}}
\end{aligned}
$$

The rice grain moved at a uniform deceleration in the vertical direction, and the instantaneous velocity in the middle is equal to the average velocity in this period.

$$
\begin{gathered}
\bar{v}_{n}=\frac{z_{n}-z_{0}}{t_{n}} \\
v_{z}=\bar{v}_{n}+\frac{1}{2} g t_{n}
\end{gathered}
$$

Equation (10), (11), and (13) are combined into Equation (9), and the relationship between the restitution coefficient and displacement variation is obtained.

$$
e=\frac{2 t_{m} \sqrt{\frac{\left(x_{n}-x_{0}\right)^{2}+\left(y_{n}-y_{0}\right)^{2}+\left(z_{n}-z_{0}\right)^{2}}{t_{n}^{2}}+g\left(z_{n}-z_{0}\right)+\frac{g^{2} t_{n}^{2}}{4}}}{2\left(z_{m}-z_{0}\right)+g t_{m}^{2}}
$$

In the process of the high-speed camera test, the restitution coefficient between rice grain and various contact materials can be calculated by collecting the coordinate values of the rice grain centroid between two pictures and substituting Equation (14).

\subsection{Test Design}

In order to study the influence of various factors on the restitution coefficient of rice grain, the contact materials, rice varieties, spring compressions, and moisture contents were selected to carry out the orthogonal test. Each test was repeated three times, and the average value was taken. The factor level coding table is shown in Table 3.

Table 3. Factor level coding table of orthogonal test for restitution coefficient.

\begin{tabular}{ccccc}
\hline Level & Contact Materials & Rice Varieties & Spring Compressions/mm & Moisture Contents/\% \\
\hline 1 & Rubber plate & Longjing 29 & 50 & 15.12 \\
2 & Q235 steel plate & Wuyudao 4 & 100 & 18.05 \\
3 & Plexiglass plate & Jijing 88 & 150 & 20.84 \\
4 & Seed plate & Shennong 9903 & 200 & 23.90 \\
\hline
\end{tabular}

Note: The moisture content of rice was the range of suitable harvest period in Northeast China after 1 October.

$\mathrm{L}_{16}\left(4^{5}\right)$ orthogonal table was used to design the test scheme. The scheme and results are shown in Table 4, and the analysis of variance is shown in Table 5. 
Table 4. Orthogonal test scheme and results of restitution coefficient.

\begin{tabular}{|c|c|c|c|c|c|c|}
\hline Order & $\begin{array}{c}\text { Contact } \\
\text { Materials(A) }\end{array}$ & $\begin{array}{c}\text { Rice } \\
\text { Varieties(B) }\end{array}$ & $\begin{array}{c}\text { Spring } \\
\text { Compres- } \\
\text { sions }(\mathrm{C}) / \mathrm{mm}\end{array}$ & $\begin{array}{c}\text { Moisture } \\
\text { Contents(D)/\% }\end{array}$ & Empty Column & $\begin{array}{l}\text { Restitution } \\
\text { Coefficient }\end{array}$ \\
\hline 1 & 1 & 1 & 1 & 1 & 1 & 0.474 \\
\hline 2 & 1 & 2 & 2 & 2 & 2 & 0.507 \\
\hline 3 & 1 & 3 & 3 & 3 & 3 & 0.509 \\
\hline 4 & 1 & 4 & 4 & 4 & 4 & 0.483 \\
\hline 5 & 2 & 1 & 2 & 3 & 4 & 0.468 \\
\hline 6 & 2 & 2 & 1 & 4 & 3 & 0.476 \\
\hline 7 & 2 & 3 & 4 & 1 & 2 & 0.489 \\
\hline 8 & 2 & 4 & 3 & 2 & 1 & 0.545 \\
\hline 9 & 3 & 1 & 3 & 4 & 2 & 0.497 \\
\hline 10 & 3 & 2 & 4 & 3 & 1 & 0.420 \\
\hline 11 & 3 & 3 & 1 & 2 & 4 & 0.397 \\
\hline 12 & 3 & 4 & 2 & 1 & 3 & 0.460 \\
\hline 13 & 4 & 1 & 4 & 2 & 3 & 0.361 \\
\hline 14 & 4 & 2 & 3 & 1 & 4 & 0.487 \\
\hline 15 & 4 & 3 & 2 & 4 & 1 & 0.394 \\
\hline 16 & 4 & 4 & 1 & 3 & 2 & 0.354 \\
\hline$K_{1}$ & 1.973 & 1.800 & 1.701 & 1.910 & 1.833 & \\
\hline$K_{2}$ & 1.978 & 1.890 & 1.829 & 1.810 & 1.847 & \\
\hline$K_{3}$ & 1.774 & 1.789 & 2.038 & 1.751 & 1.806 & \\
\hline$K_{4}$ & 1.596 & 1.842 & 1.753 & 1.850 & 1.835 & \\
\hline$k_{1}$ & 0.493 & 0.450 & 0.425 & 0.478 & 0.458 & \\
\hline$k_{2}$ & 0.495 & 0.473 & 0.457 & 0.453 & 0.462 & \\
\hline$k_{3}$ & 0.444 & 0.447 & 0.510 & 0.438 & 0.452 & \\
\hline$k_{4}$ & 0.399 & 0.461 & 0.438 & 0.463 & 0.459 & \\
\hline$R$ & 0.096 & 0.026 & 0.085 & 0.040 & 0.010 & \\
\hline $\begin{array}{c}\text { Factor } \\
\text { arrangement }\end{array}$ & \multicolumn{6}{|c|}{$A>C>D>B$} \\
\hline
\end{tabular}

Note: $K_{1} \sim K_{4}$ and $k_{1} \sim k_{4}$ represent the sum and average value of restitution coefficient under each factor and level respectively; $R$ is the range.

Table 5. Analysis of variance of orthogonal test for restitution coefficient.

\begin{tabular}{ccccccc}
\hline Source of Variance & $\begin{array}{c}\text { Derivate } \\
\text { Square }\end{array}$ & $\begin{array}{c}\text { Degree of } \\
\text { Freedom }\end{array}$ & $\begin{array}{c}\text { Mean of } \\
\text { Derivate } \\
\text { Square }\end{array}$ & F Value & $p$ Value & Significance \\
\hline Contact materials & 0.025000 & 3 & 0.008354 & 111.54 & 0.0014 & $* .0717$ \\
Rice varieties & 0.001581 & 3 & 0.000527 & 7.04 & 0.0026 & $* 0261$ \\
Spring compressions & 0.016000 & 3 & 0.005486 & 73.25 & \\
Moisture contents & 0.003360 & 3 & 0.001120 & 14.95 & \\
Error & 0.000225 & 3 & 0.000075 & & \\
Sum & 0.047 & 15 & & & \\
\hline
\end{tabular}

Note: $p<0.01$ indicates extremely significant $(* *) ; p<0.05$ indicates significant $\left({ }^{*}\right)$.

According to the analysis, the primary and secondary factors affecting the restitution coefficient of rice grain were contact materials, spring compressions, moisture contents, and rice varieties. Among them, the contact materials and spring compressions had an extremely significant effect on the restitution coefficient, and moisture content has a significant effect on the restitution coefficient.

In order to explore the influence of different factors on the restitution coefficient of rice grain further, the single factor test was carried out for the significant factors. Among them, rubber plate, Q235 steel plate, plexiglass plate, and seed plate were selected as contact materials. The single factor values of spring compressions were $50 \mathrm{~mm}, 100 \mathrm{~mm}, 150 \mathrm{~mm}$, $200 \mathrm{~mm}$, and $250 \mathrm{~mm}$, respectively. The single factor values of moisture content were $15.03 \%, 17.22 \%, 18.91 \%, 21.03 \%, 22.95 \%$, and $24.94 \%$, respectively. 


\subsection{Simulation Calibration}

To verify the accuracy of the restitution coefficient in EDEM simulation process, taking "Long Jing 29" rice grain as the research object, combined with the high-speed camera bench test, the bouncing and collision state of rice grain was simulated and analyzed. In the actual bench test process, the collision angle was adjusted to $0^{\circ}$, and the contact material was set as the plexiglass plate. The moisture content of rice grain was $20.06 \%$; the initial position was $150 \mathrm{~mm}$ away from the impact platform; and the spring compression was $200 \mathrm{~mm}$. In order to simulate the velocity and motion state in the process of impact in the simulation process accurately, according to the motion state of rice grain continuously captured by the high-speed camera, the starting point of the rice grain simulation was $150 \mathrm{~mm}$ away from the collision platform. The calculated speed of the actual photograph was taken as the initial speed of the simulation and applied to the established rice grain model.

\subsubsection{Establishment of Simulation Model}

To establish an accurate simulation model of rice grain, the rice grain was scanned by the Reeyee X5 3D laser scanner (Nanjing Weibo 3D Technology Co., Ltd., Nanjing, China). Then, the position coordinate point data of the surface were obtained, and the accurate model and physical parameters were obtained through point cloud processing, denoising, and reverse modeling operations [23-25]. The scanning model was imported into edem2018 software to build a discrete element model in the form of multi-sphere combination [26], as shown in Figure 5.

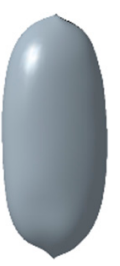

(a)

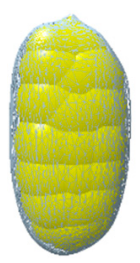

(b)

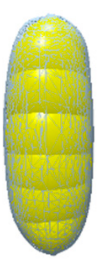

(c)

Figure 5. Rice grain model: (a) scanning model; (b) front filling of discrete element model; (c) side filling of discrete element model.

\subsubsection{Parameters Setting of Simulation}

To ensure the accuracy of the simulation parameters setting, it is necessary to test other simulation parameters. In the actual test process, each test was repeated three times, and the average value was taken. According to the rice grain with $20.06 \%$ moisture content, the volume was measured by the liquid level method [27], and the density was converted to $1095 \mathrm{~kg} / \mathrm{m}^{3}$ according to the mass relationship. According to the relevant references [28-30], the static friction coefficient and rolling friction coefficient of rice grain are 0.252 and 0.026 , respectively, and the shear modulus of rice grain is $1.81 \times 10^{8} \mathrm{~Pa}$. The simulation parameters of rice grain and contact material (plexiglass plate) were obtained, as shown in Table 6.

Table 6. Simulation parameters of rice grain and contact material.

\begin{tabular}{cccc}
\hline Parameter & Rice Grain & Plexiglass Plate \\
\hline Density $/\left(\mathrm{kg} / \mathrm{m}^{3}\right)$ & 1095 & & 1180 \\
Poisson's ratio & 0.25 & & 0.50 \\
Shear modulus $/ \mathrm{Pa}$ & $1.81 \times 10^{8}$ & & $1.77 \times 10^{8}$ \\
Static friction coefficient & & 0.252 & \\
Rolling friction coefficient & & 0.026 & \\
Restitution coefficient & & 0.429 & \\
\hline
\end{tabular}


In the simulation experiment, the total number of grain generated was set as 1 , and the generation time was set as $0.001 \mathrm{~s}$. In order to ensure the continuity of the simulation calibration, the fixed time step was set as $8.01 \times 10^{-7} \mathrm{~s}$, which was $10 \%$ of Rayleigh time step, and the total time was $1 \mathrm{~s}$.

\section{Results and Discussion}

\subsection{Results Analysis of Single Factor}

The orthogonal test showed that the contact materials had an extremely significant effect on the coefficient of restitution of rice grain. The single factor test further showed that the restitution coefficient between rice grain and all kinds of contact materials was the Q235 steel plate, plexiglass plate, seed plate, and rubber plate in descending order. The values of Longjing 29 were 0.567, 0.513, 0.508, 0.485; of Wuyoudao 4 were 0.497, 0.477, $0.465,0.430$; of Jijing 88 were $0.541,0.534,0.529,0.461$; and of Shennong 9903 were 0.535, $0.518,0.502,0.477$, respectively, as shown in Figure 6.

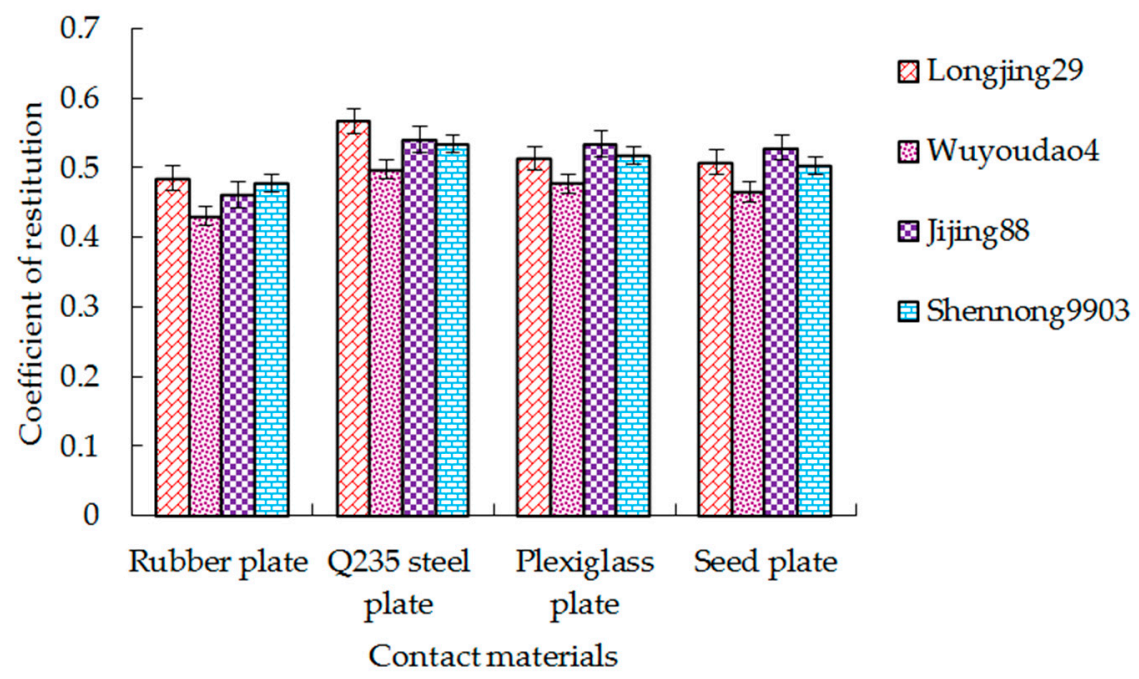

Figure 6. Effect of contact materials on restitution coefficient of rice grain. Note: The compression of spring was $150 \mathrm{~mm}$, and the moisture content was $18.91 \%$.

The contact and collision between rice grain and various materials were a very complex process of energy change. During the process of point line plane collision, the rice grain experienced two stages of deformation and recovery, including not only the deformation and recovery of the rice grain surface, but also the relative motion within each material layer [31]. The whole collision process satisfied the law of conservation of energy. When the rice grain fell freely from a certain height, the influence of air resistance on the grain was ignored, and the gravitational potential energy was converted into kinetic energy. The potential energy was the minimum, and kinetic energy reached the maximum immediately before the collision. During the collision, both the rice grain and the collision material produced a certain amount of deformation, and the surface friction of the collision material did work on the rice grain. The collision deformation mainly included elastic deformation and plastic deformation. In the compression stage, part of the kinetic energy was transformed into elastic potential energy produced by elastic deformation, and the other part was transformed into internal energy produced by friction and plastic deformation. In the recovery stage, one part of the elastic potential energy was converted into kinetic energy; the other part was converted into internal energy by friction and potential energy by overcoming gravity. When the rice grain leaves the surface of the contact material, the kinetic energy was transformed into the rebound speed of the rice grains, which made the rice grains rise to a certain height.

Because the hardness of the Q235 steel plate was the largest, the contact area of rice grain and its impact was small, and the deformation of steel plate was small, which led 
to the large restitution coefficient of rice grain. However, the hardness of the rubber plate was small, and the contact area of rice grain and its impact was large, and the deformation was large. Most of the energy generated by the collision of rice grains was absorbed by the rubber plate, which played a certain buffer role and made the restitution coefficient of rice grains small.

The effect of spring compression on the restitution coefficient of rice grain is second only to the contact materials. The amount of spring compression defined the initial velocity of rice grain in the test of the restitution coefficient. The single factor test showed that the restitution coefficient decreased with the increased spring compression. The quadratic regression equations between the spring compression and the restitution coefficient of Long Jing 29, Wu Youdao 4, Ji Jing 88, and Shen Nong 9903 were obtained. The quadratic regression equations can be used to analyze and predict the relationship between the restitution coefficient of different rice varieties and spring compression, as shown in Figure 7. $R^{2}$ was used to measure the overall fitting degree of the regression equation. From Figure 7, the minimum value of $R^{2}$ was 0.985 , indicating that the quadratic regression equation had a high fitting degree and good predictability. Because the larger the spring compression was, the greater the initial velocity of collision was. When rice grain collided, the more impulses were obtained in unit time, and the larger the deformation was, the smaller the restitution coefficient was. The smaller the spring compression was, the smaller the initial velocity was, the less the impulse was, the smaller the deformation was, and the greater the coefficient of restitution was.

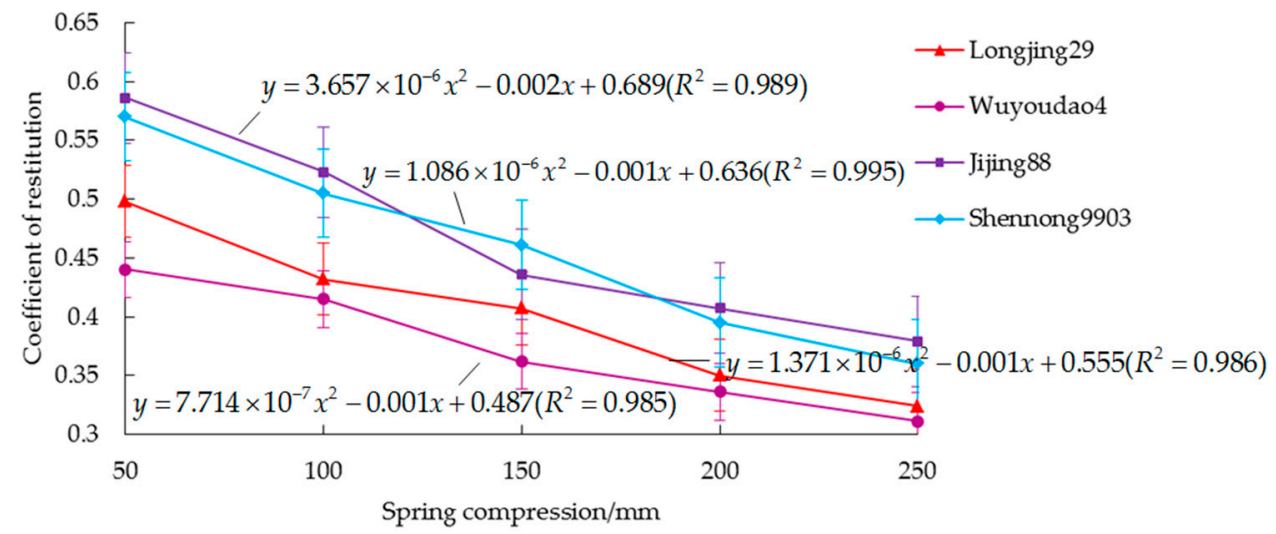

Figure 7. Effect of spring compression on restitution coefficient of rice grain. Note: In the test, the contact material was plexiglass plate, and the moisture content was $18.91 \%$.

With the increased moisture content, the restitution coefficient of rice grain gradually decreased. The quadratic regression equation of moisture content and restitution coefficient of Longjing 29, Wuyoudao 4, Jijing 88, and Shennong 9903 were obtained. The quadratic regression equations can be used to analyze and predict the relationship between the restitution coefficient of different rice varieties and moisture content, as shown in Figure 8. $R^{2}$ was used to measure the overall fitting degree of the regression equation. From Figure 8 , the minimum value of $R^{2}$ was 0.968 , indicating that the quadratic regression equation had a high fitting degree and good predictability. The higher the moisture content of rice grain was, the greater the deformation of rice grain was when it collided with the contact material, and the greater viscosity was, the greater the energy loss during the collision process. Therefore, the normal separation velocity of rice grain rebounding after collision with contact material was reduced, and finally the restitution coefficient of rice grain was reduced. 


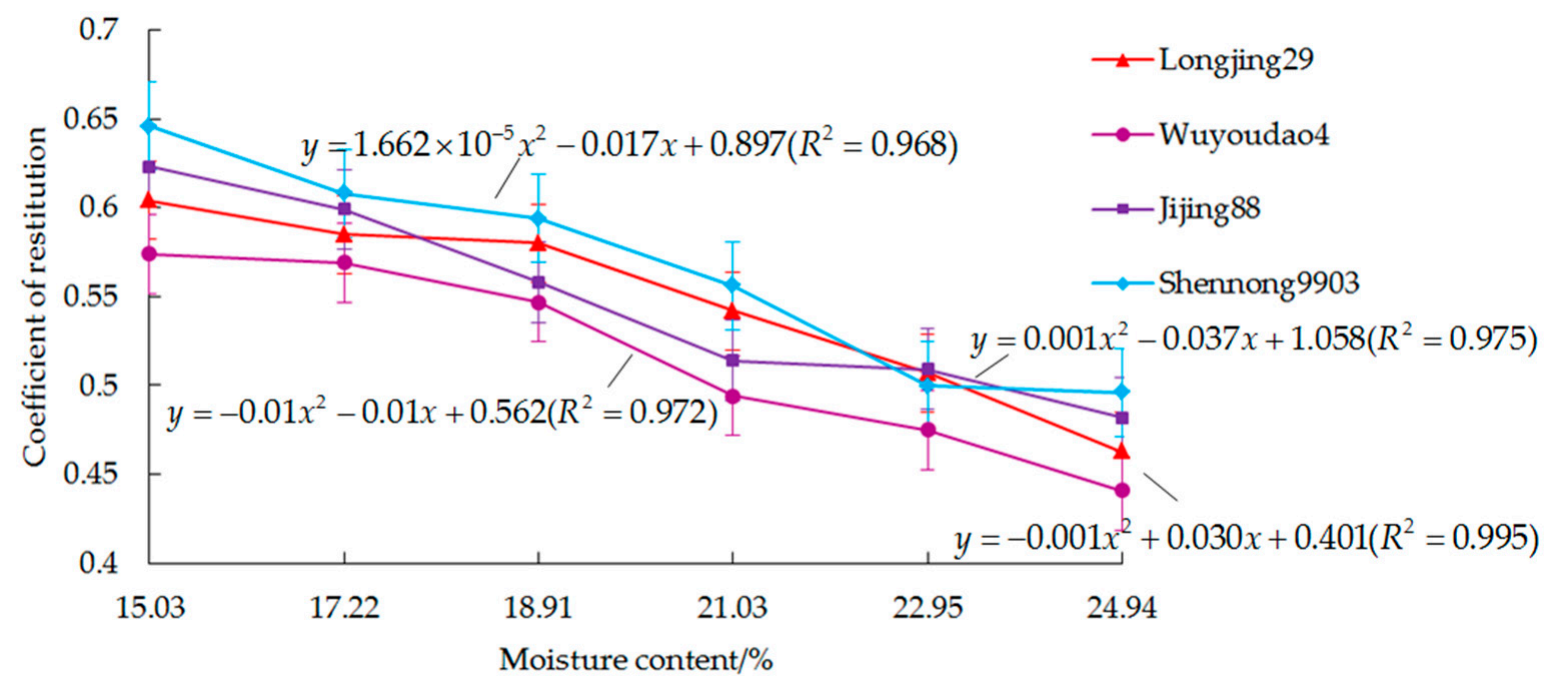

Figure 8. Effect of moisture content on restitution coefficient of rice grain. Note: In the test, the spring compression was $150 \mathrm{~mm}$, and the contact material was plexiglass plate.

\subsection{Results Analysis of Simulation Calibration}

To avoid accidental errors in the test process, the bench test and simulation test were repeated three times, and the motion parameters were determined as the test results. The vertical falling direction of rice grain was $X$ direction; the left and right direction was $Y$ direction; and the front and back direction was $Z$ direction. The bouncing state of rice grains obtained by the bench test and simulation test is shown in Figures 9 and 10.

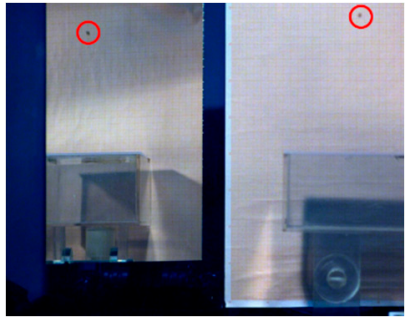

(a)

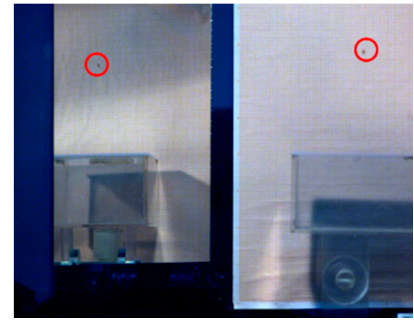

(b)

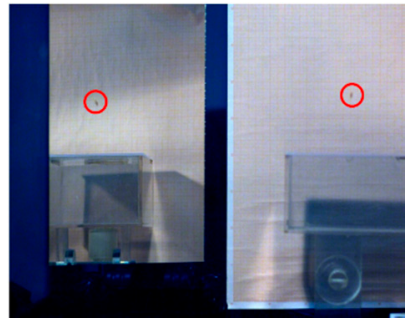

(c)

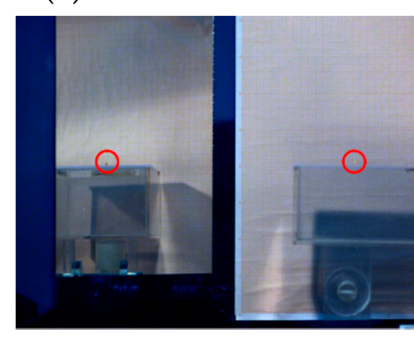

(d)

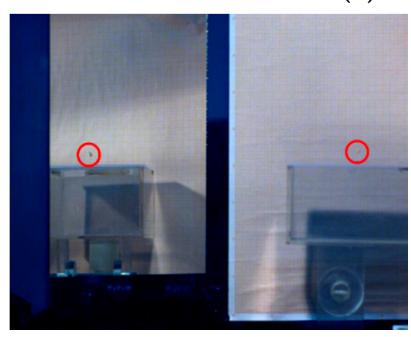

(e)

Figure 9. Rice grain bouncing state of bench test. The picture shows the falling state of grains at different times: (a) $0.01 \mathrm{~s}$; (b) $0.04 \mathrm{~s}$; (c) $0.07 \mathrm{~s}$; (d) $0.10 \mathrm{~s}$; and (e) $0.13 \mathrm{~s}$. 

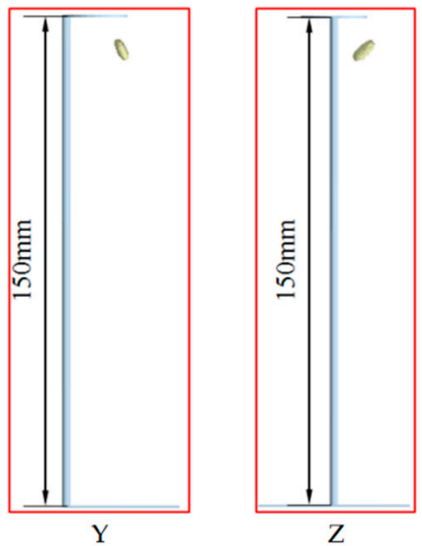

(a)
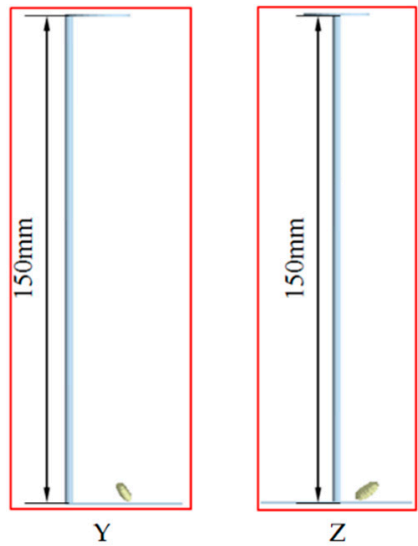

(d)
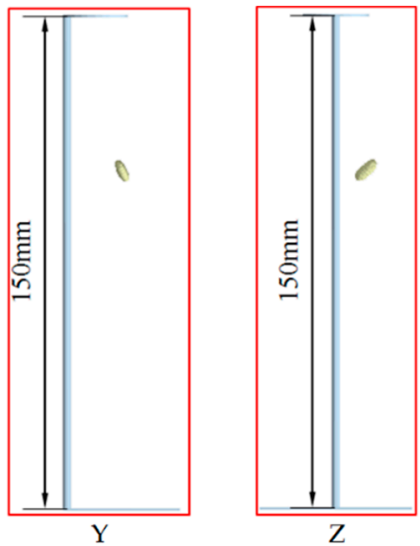

(b)
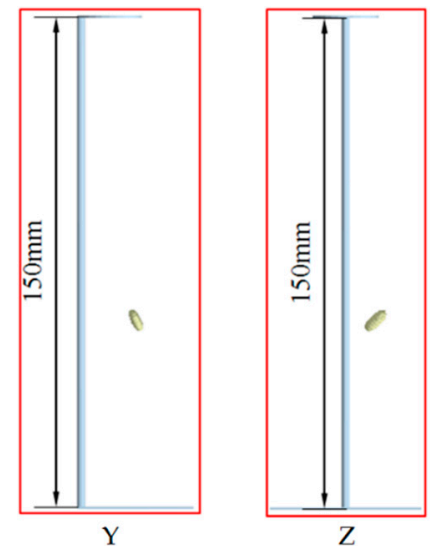

(c)
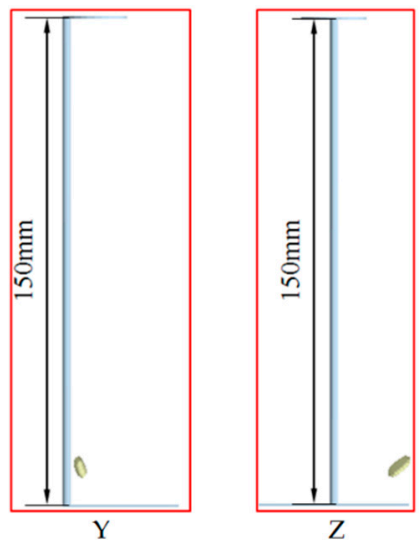

(e)

Figure 10. Rice grain bouncing state of simulation test. The picture shows the falling state of grains at different times: $Y$ is the $\mathrm{Y}$ direction, and $\mathrm{Z}$ is the $\mathrm{Z}$ direction. (a) $0.01 \mathrm{~s}$; (b) $0.04 \mathrm{~s}$; (c) $0.07 \mathrm{~s}$; (d) $0.10 \mathrm{~s}$; and (e) $0.13 \mathrm{~s}$.

To analyze intuitively and accurately the whole process of rice grain from falling to collision rebound, the regular curve of the relationship between vertical displacement, combined velocity (absolute value), and movement time in the process of the bench test and simulation test was drawn, as shown in Figure 11.

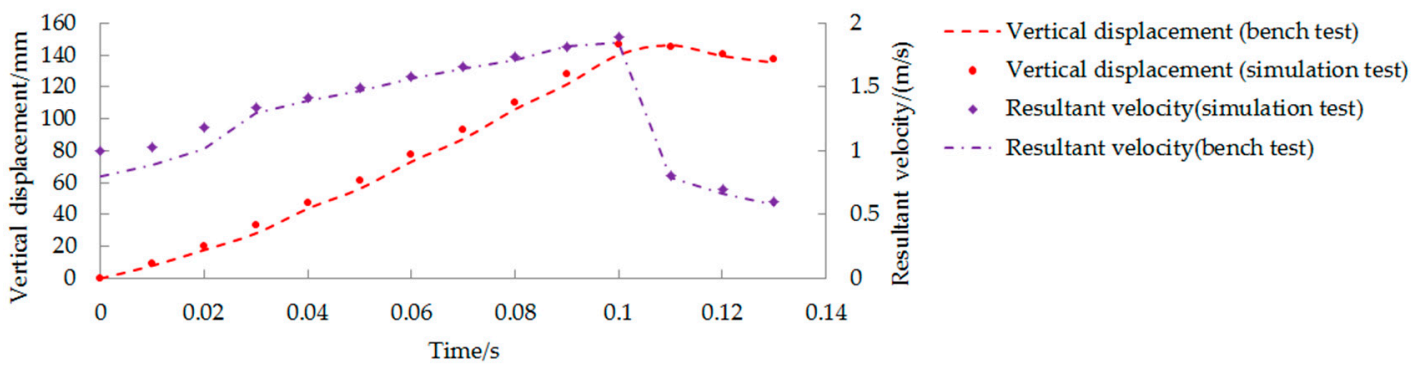

Figure 11. Curve of rice grain collision.

It can be seen from Figures 9-11 that there was a certain initial velocity at $0 \mathrm{~s}$ in the bench test and simulation test, which was the velocity of rice grain after being ejected by the impact device. With the increased time, the vertical displacement and resultant velocity increased gradually. When the time was $0.10 \mathrm{~s} \sim 0.12 \mathrm{~s}$, the vertical displacement reached the maximum, and the combined velocity decreases sharply. At this time, the rice grain collided with the plexiglass plate, and the ratio of combined velocity after collision to that before collision was the restitution coefficient of rice grain. With the increased time, the 
rice grain rebounded to a certain height, but the direction of motion was opposite to the direction of gravity acceleration, resulting in the speed gradually decreased.

The velocity of rice grain measured by the bench test was less than that of simulation test. The velocity before collision was $1.851 \mathrm{~m} / \mathrm{s}$, and the velocity after collision was $0.794 \mathrm{~m} / \mathrm{s}$ in the bench test, so the restitution coefficient was 0.429 . The velocity before collision was $1.895 \mathrm{~m} / \mathrm{s}$, and the velocity after collision was $0.802 \mathrm{~m} / \mathrm{s}$ in the simulation test, so the restitution coefficient was 0.423 . Compared with the preset value, the relative error was $1.40 \%$. This may be due to the influence of air resistance in the bench test, while the influence of air resistance was ignored in the simulation test, or the discrete element model of rice grain was composed of several small spheres, which increased the surface area of rice grain and led to large energy loss in the contact part during the bouncing collision. At the same time, due to the irregular shape of rice grain, it was easy to produce displacement and velocity in other directions of the three-dimensional space after bouncing, which had a certain impact on the subsequent measurement and analysis results. Because the speed of rice grain before collision in the bench test was less than that before collision in the simulation test, the restitution coefficient in the bench test was greater than that in the simulation test, which also verified the conclusion in 3.1.2 that the greater the initial collision speed was, the smaller the coefficient of restitution was. The results were consistent with the research results of Feng et al. [10] and Liu et al. [11]. However, the overall difference between the bench test and the simulation test was small, which proved the validity and rationality of the determination and simulation of the calibration restitution of rice grain.

To analyze the reasons for the difference of the restitution coefficient between bench test and simulation test further, the movement state of rice grain before and after collision was compared, as shown in Figure 12. In the process of the bench test and simulation test, the movement state, direction, and speed of rice grains changed significantly after the impact. In the process of bouncing, the rice grains rotated. This led to the phenomenon that when the rice grains left the surface of the contact material, the kinetic energy was not only converted into the rebound speed of rice grains, but also consumed part of the kinetic energy by the rotation of the rice grains. This is also the reason for the difference of the rice grain restitution coefficient between the bench test and simulation test. Due to the randomness of the rotation speed of rice grain, it cannot be calculated quantitatively, which was also the deficiency of this study. In the later stage, the calculation of the moment of inertia of rice grain and the analysis of rotation state after collision will be further studied to make the calculation and verification of the restitution coefficient of rice grain more accurate.

\subsection{Discussion}

According to the influence of contact materials on the restitution coefficient of rice grain, the greater the hardness of materials, the greater the restitution coefficient of rice grain. To reduce the splash loss and breakage rate of rice grain in the harvesting process, rubber protection devices can be set on the header of the combine harvester. In addition, rubber type flexible threshing elements can be used in the threshing drum to reduce the breakage rate and ensure rice grain harvest quality. For the working parts that need to increase grain rebound to improve the material circulation, such as the cleaning screen of the combine harvester and seed metering plate, the material with the larger recovery coefficient can be used.

According to the influence of spring compressions (initial velocity of rice grain) on the restitution coefficient of rice grain, the greater the spring compression, the greater the initial velocity, and the smaller the restitution coefficient, that is, the greater the velocity difference. In the design and development of the key components of the high-speed precision metering device, such as seed filling, seed protection, seed cleaning, and seed feeding, the initial speed of rice grains should be minimized to maintain the stability in the process of migration. At the same time, how to design the structure of the seed metering 


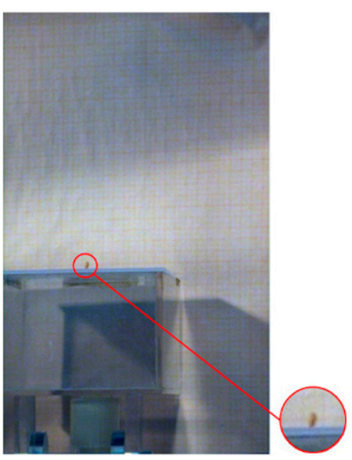

(a)

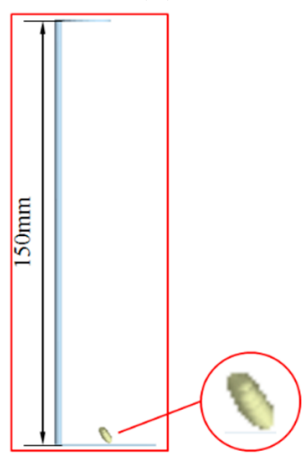

(e)

device to achieve zero speed seeding, reduce the collision of seeds in the seed guide tube, so as to achieve the goal of low multiples and leak index and high qualified index, is one of the directions.

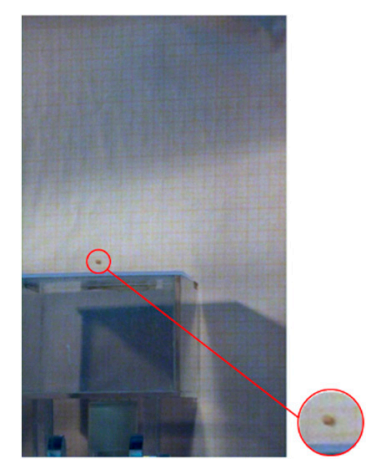

(b)

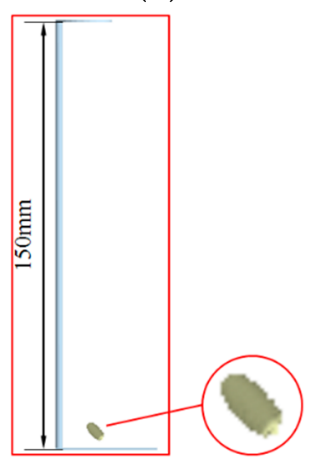

(f)

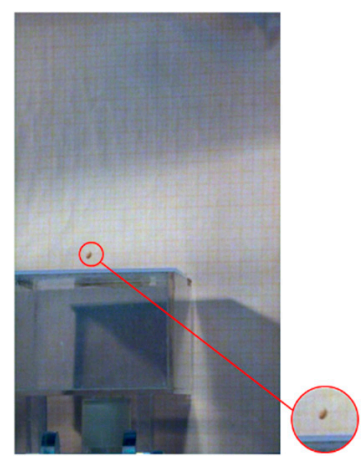

(c)

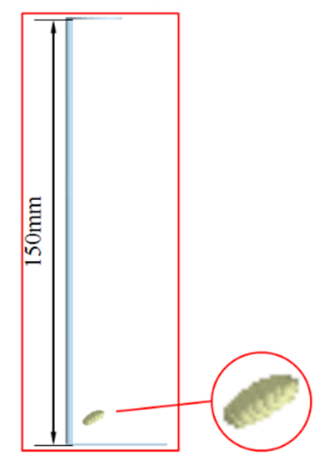

(g)

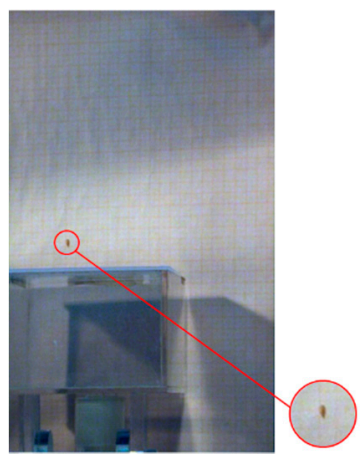

(d)

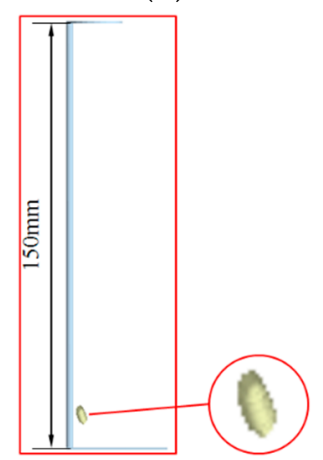

(h)

Figure 12. Comparison of motion state of rice grain before and after collision. $(\mathbf{a}-\mathbf{d})$ is the bench test; (e-h) is the simulation test: (a) before collision $(0.10 \mathrm{~s} Y$ state); (b) after collision $(0.11 \mathrm{~s} Y$ state); (c) after collision $(0.12 \mathrm{~s} Y$ state); (d) after collision ( $0.13 \mathrm{~s}$ Y state); (e) before collision ( $0.10 \mathrm{~s}$ Y state); (f) after collision ( $0.11 \mathrm{~s} Y$ state); (g) after collision ( $0.12 \mathrm{~s} Y$ state); and (h) after collision ( $0.13 \mathrm{~s} Y$ state).

According to the effect of moisture content on the restitution coefficient of rice grain, the higher the moisture content was, the smaller the restitution coefficient was. In the process of rice harvest, rice should be harvested under the condition of appropriate moisture content. Rice grains are directly contacted with the rigid material of the combine harvester in the process of conveying, threshing, and cleaning. When the moisture content of rice grains is high, the deformation of rice grains is large, and the restitution coefficient is small, which is easy to increase the grain breakage rate. At the same time, the moisture content of the rice stem is relatively high, which is easy to block in the screw pusher, inclined conveyor, and threshing chamber of the combine harvester, affecting the quality and efficiency of harvesting working. In addition, high-moisture-content rice is not easy to store after harvest. It needs an additional drying process, which increases the production cost. However, the moisture content during harvesting should not be too low. When the combine harvester is working, the rigid and hard contact between the reel on the header assembly and the upright rice is easy to cause a large loss of header and a large area of grain loss. Therefore, the best harvest time is from the late waxy stage to the early mature stage of rice, and the moisture content is generally $15 \sim 21 \%$ [32].

Because of the randomness of the rotation speed of rice grain, it cannot be calculated quantitatively. At the same time, the rotation also led to the contact parts of rice grains not to be accurately controlled, and the influence of air resistance was ignored in the process of the test, resulting in certain errors, which is also the deficiency of this study. In the later stage, the calculation of the moment of inertia of rice grain and the analysis of the rotational state after collision will be studied in depth. At the same time, the measuring device of the 
restitution coefficient will be improved, and the vacuum environment will be set on the path between the seed dropping opening and the contact material to avoid the influence of air resistance, so as to make the calculation and verification of the restitution coefficient more accurate.

In the orthogonal test, the contact materials, rice varieties, spring compressions, and moisture contents were taken as the test factors to analyze the restitution coefficient. The results showed that the contact materials, rice varieties, and spring compressions had a significant impact on the restitution coefficient, while the rice varieties had no significant impact on the restitution coefficient. Therefore, this study makes a single factor analysis on the factors that have a significant impact on the restitution coefficient. Rice varieties are mainly affected by moisture content and triaxial size. In the later stage, a comparative study on restitution coefficient of multiple varieties in the main rice-producing areas of China will be carried out to provide data support for the restitution coefficient of multi-variety rice grains. In addition, this method can provide theoretical support for the determination of the restitution coefficient of small grains such as rice, wheat, and sorghum.

\section{Conclusions}

In this paper, an impact method was proposed to determine the restitution coefficient of rice grain, and a test device was designed. The test principle was described and extended from a horizontal angle collision to a general angle collision. Through the orthogonal test, the results showed that the contact materials and spring compressions had a significant effect on the restitution coefficient of rice grain; the moisture contents had a significant effect on the restitution coefficient of rice grain; and the rice varieties had no significant effect on the restitution coefficient of rice grain. This paper focused on the single factor test of the significant factors, explored the impact law of the restitution coefficient, and fitted the regression equation, which can accurately predict the impact of various factors on the restitution coefficient. The results of the single factor test showed that the restitution coefficient between rice grain and various contact materials were Q235 steel plate, plexiglass plate, seed plate, and rubber plate in descending order; the larger the spring compression (the higher the initial velocity), the smaller the restitution coefficient; the higher the moisture content of rice grain, the smaller the restitution coefficient. To explore the accuracy of the proposed method, the high-speed camera was used to capture the bouncing state of rice grains. Compared with the EDEM simulation test, the obtained restitution coefficients were 0.429 and 0.423 , and the relative error was $1.40 \%$.

In this study, the existence of air resistance is ignored, but it exists in the bench test. At the same time, due to the rotation of rice grains in the process of falling, the air resistance is different at different times, which cannot be accurately calculated. In the later stage, the calculation of the moment of inertia of rice grain and the analysis of the rotational state after collision will be studied in depth. At the same time, the measuring device of the restitution coefficient will be improved, so as to make the calculation and verification of the restitution coefficient more accurate.

Author Contributions: Conceptualization, J.W. (Jinwu Wang) and C.X.; methodology, C.X.; software, Y.X. and X.Q.; validation, Z.W.; investigation, X.Q. and H.T.; resources, J.W. (Jinwu Wang); data curation, H.T. and Z.W.; writing-original draft preparation, C.X. and H.T.; writing-review and editing, J.W. (Jinwu Wang), J.W. (Jinfeng Wang), Q.W., W.Z., and H.T.; visualization, C.X.; supervision, H.T. and Q.W.; funding acquisition, J.W. (Jinwu Wang) and H.T. All authors have read and agreed to the published version of the manuscript.

Funding: This work was funded by the National Natural Science Foundation of China (NSFC), grant number: 31901414; the Postdoctoral Science Foundation of Heilongjiang Province, grant number: LBH-Z19007; the Program on Industrial Technology System of National Rice (CN), grant number: CARS-01-44.

Institutional Review Board Statement: Not applicable.

Informed Consent Statement: Not applicable. 
Data Availability Statement: All data are presented in this article in the form of figures and tables.

Acknowledgments: The authors would like to acknowledge the College of Engineering, Northeast Agricultural University, and the Key Laboratory of Crop Harvesting Equipment Technology of Zhejiang Province.

Conflicts of Interest: The authors declare no conflict of interest.

\section{References}

1. Zhao, H.; Mo, Z.; Lin, Q.; Pan, S.; Duan, M.; Tian, H.; Wang, S.; Tang, X. Relationships between grain yield and agronomic traits of rice in southern China. Chil. J. Agric. Res. 2020, 80, 72-79. [CrossRef]

2. $\quad$ Dong, F.; Xu, J.H.; Shi, J.R.; Mokoena, M.P.; Olaniran, A.O.; Chen, X.Y.; Lee, Y.-W. First Report of Fusarium Head Blight Caused by Fusarium meridionale in Rice in China. Plant Dis. 2020, 104, 2726. [CrossRef]

3. Chen, D.; Ye, X.; Zhang, Q.; Xiao, W.; Ni, Z.; Yang, L.; Zhao, S.; Hu, J.; Gao, N.; Huang, M. The effect of sepiolite application on rice Cd uptake-A two-year field study in Southern China. J. Environ. Manag. 2020, 254, 109788. [CrossRef]

4. Zhou, M.; Wang, H.; Yang, S.; Fan, K. Influence of springtime North Atlantic Oscillation on crops yields in Northeast China. Clim. Dyn. 2013, 41, 3317-3324. [CrossRef]

5. Petkevichius, S.; Shpokas, L.; Kutzbach, H.D. Investigation of the maize ear threshing process. Biosyst. Eng. 2008, 99, 532-539. [CrossRef]

6. Tamura, M.; Singh, J.; Kaur, L.; Ogawa, Y. Impact of structural characteristics on starch digestibility of cooked rice. Food Chem. 2016, 191, 91-97. [CrossRef] [PubMed]

7. Wang, L.; Zheng, Z.; Yu, Y.; Liu, T.; Zhang, Z. Determination of the energetic coefficient of restitution of maize grain based on laboratory experiments and DEM simulations. Powder Technol. 2020, 362, 645-658. [CrossRef]

8. Lun, C.K.K.; Savage, S.B. The effects of an impact velocity dependent coefficient of restitution on stresses developed by sheared granular materials. Acta Mech. 1986, 63, 15-44. [CrossRef]

9. Mangwandi, C.; Cheong, Y.S.; Adams, M.J.; Hounslow, M.J.; Salman, A.D. The coefficient of restitution of different representative types of granules. Chem. Eng. Sci. 2007, 62, 437-450. [CrossRef]

10. Feng, B.; Sun, W.; Shi, L.; Sun, B.; Zhang, T.; Wu, J. Determination of restitution coefficient of potato tubers collision in harvest and analysis of its influence factors. Nongye Gongcheng Xuebao/Trans. Chin. Soc. Agric. Eng. 2017, 33, 50-57. [CrossRef]

11. Liu, Y.; Zong, W.; Ma, L.; Huang, X.; Li, M.; Tang, C. Determination of three-dimensional collision restitution coefficient of oil sunflower grain by high-speed photography. Nongye Gongcheng Xuebao/Trans. Chin. Soc. Agric. Eng. 2020, 36, 44-53. [CrossRef]

12. Liu, C.; Wang, Y.; Song, J.; Wang, C.; Li, Y. Experimental determination and simulation verification of granular material restitution coefficient. Int. Agric. Eng. J. 2016, 25, 48-56.

13. Horabik, J.; Beczek, M.; Mazur, R.; Parafiniuk, P.; Ryżak, M.; Molenda, M. Determination of the restitution coefficient of seeds and coefficients of visco-elastic Hertz contact models for DEM simulations. Biosyst. Eng. 2017, 161, 106-119. [CrossRef]

14. Marinack, M.C.; Jasti, V.K.; Choi, Y.E.; Higgs, C.F. Couette grain flow experiments: The effects of the coefficient of restitution, global solid fraction, and materials. Powder Technol. 2011, 211, 144-155. [CrossRef]

15. Xu, Y.; Zhang, X.; Wu, S.; Chen, C.; Wang, J.; Yuan, S.; Chen, B.; Li, P.; Xu, R. Numerical simulation of particle motion at cucumber straw grinding process based on EDEM. Int. J. Agric. Biol. Eng. 2020, 13, 227-235. [CrossRef]

16. XiaoLong, L.; YiTao, L.; QingXi, L. Simulation of seed motion in seed feeding device with DEM-CFD coupling approach for rapeseed and wheat. Comput. Electron. Agric. 2016, 131, 29-39.

17. Su, Z.; Li, Y.; Dong, Y.; Tang, Z.; Liang, Z. Simulation of rice threshing performance with concentric and non-concentric threshing gaps. Biosyst. Eng. 2020, 197, 270-284. [CrossRef]

18. Horabik, J.; Parafiniuk, P.; Molenda, M. Stress profile in bulk of seeds in a shallow model silo as influenced by mobilisation of particle-particle and particle-wall friction: Experiments and DEM simulations. Powder Technol. 2018, 197, 270-284. [CrossRef]

19. Fields, P.; Korunic, Z. The effect of grain moisture content and temperature on the efficacy of diatomaceous earths from different geographical locations against stored-product beetles. J. Stored Prod. Res. 2000, 36, 1-13. [CrossRef]

20. Tarui, F.; Takeuchi, M.; Kubo, H. Investigations on Drying Method of High Moisture Paddy at Rice-Center. Jpn. J. Farm Work Res. 1969, 1969, 58-61. [CrossRef]

21. Wang, J.W.; Han, T.; Wang, J.F.; Jiang, D.X.; Li, X. Measurement and analysis of restitution coefficient between maize seed and soil based on high-speed photography. Int. J. Agric. Biol. Eng. 2017, 10, 102-114. [CrossRef]

22. Dong, M.; Mei, Y.; Li, X.; Shang, Y.; Li, S. Experimental measurement of the normal coefficient of restitution of micro-particles impacting on plate surface in different humidity. Powder Technol. 2018, 335, 250-257. [CrossRef]

23. Sakai, N.; Yonekawa, S. Three-dimensional image analysis of the shape of soybean seed. J. Food Eng. 1992, 15, 221-234. [CrossRef]

24. Giammanco, I.M.; Maiden, B.R.; Estes, H.E.; Brown-Giammanco, T.M. Using 3D laser scanning technology to create digital models of hailstones. Bull. Am. Meteorol. Soc. 2017, 98, 1341-1347. [CrossRef]

25. Gu, D.; Chen, Y.; Dai, K.; Zhang, S.; Yuan, J. The shape of the acetabular cartilage surface: A geometric morphometric study using three-dimensional scanning. Med. Eng. Phys. 2008, 30, 1024-1031. [CrossRef]

26. Zhou, H.; Chen, Y.; Sadek, M.A. Modelling of soil-seed contact using the Discrete Element Method (DEM). Biosyst. Eng. 2014, 121, 56-66. [CrossRef] 
27. DKADA, T. Studies on Green Panic Seed: II. Method for measuring the volume weight of a small amount of seed. J. Jpn. Soc. Grassl. Sci. 1978, 24, 137-141. [CrossRef]

28. Wang, J.; Jiang, Y.; Tang, H.; Xu, C.; Wang, Z. Physical characteristics determination and principal components analysis of typical single cropping rice in cold areas of north China. Int. Agric. Eng. J. 2020, 9, 309.

29. Yu, L.; Witt, T.; Rincon Bonilla, M.; Turner, M.S.; Fitzgerald, M.; Stokes, J.R. New insights into cooked rice quality by measuring modulus, adhesion and cohesion at the level of an individual rice grain. J. Food Eng. 2019, 240, 21-28. [CrossRef]

30. Zeng, Y.; Jia, F.; Xiao, Y.; Han, Y.; Meng, X. Discrete element method modelling of impact breakage of ellipsoidal agglomerate. Powder Technol. 2019, 346, 57-69. [CrossRef]

31. Zaimar; Mursalim; Abbas, H. Supratomo Analysis of impact velocity of rice grain on impeller speed variation in the centrifugal flow thresher by using CFD. ARPN J. Eng. Appl. Sci. 2019, 14, 962-966.

32. Bautista, R.C.; Siebenmorgen, T.J.; Mauromoustakos, A. The role of rice individual kernel moisture content distributions at harvest on milling quality. Trans. ASABE 2009, 52, 1493-1504. [CrossRef] 